\title{
Biologia/Genética: $O$ ensino de biologia, com enfoque a genética, das escolas públicas no Brasil - breve relato e reflexão
}

\section{Biology/Genetics: The teaching of biology with a focus on genetics, public schools in Brazil - brief report and reflection}

\author{
Joseane Moura'; Maria do Socorro Meireles de Deus²; Nilda Masciel Neiva \\ Gonçalves ${ }^{3}$; Ana Paula Peron ${ }^{4}$
}

\begin{abstract}
Resumo
Este trabalho teve por objetivo realizar uma breve revisão de literatura e reflexão sobre o ensino de biologia abordado nas séries do ensino médio das escolas públicas brasileiras. Com este estudo verificouse que o ensino dessa ciência ainda é considerado abstrato, sem conexão com fatos da realidade e distanciado da sociedade no qual os alunos estão inseridos, principalmente quando os tópicos abordados são da área de genética. Verifica-se que estes tópicos são considerados de difícil entendimento gerando uma alienação por parte de um grande número de alunos principalmente quando os conteúdos são tecnologias e produtos advindos dessa área. Portanto, este relato sugere que o ensino de biologia, seja a cada dia mais, repensado de forma coerente e contextualizado frente à realidade do aluno.
\end{abstract}

Palavras-chaves: Educação. Escolas. Alunos. Sociedade.

\begin{abstract}
This study aimed to conduct a brief literature review and reflection on biology teaching approached the high school grades of Brazilian public schools. With this study it was found that teaching this science is still considered abstract, unrelated facts of reality and alienated from the society in which students are placed, especially when the topics covered are the genetics area. It appears that these threads are considered difficult to understand generating a disposition by a large number of students especially when the contents are technologies and products arising from this area. Therefore, this report suggests that the teaching of biology is every day more, rethought consistently and contextualized front of the student's reality.
\end{abstract}

Keywords: Education. Schools. Students. Society.

\footnotetext{
${ }^{1}$ Universidade Federal do Piauí. E-mail: joseanenmoura@hotmail.com.

${ }^{2}$ Universidade Federal do Piauí. E-mail: socorro_meireles@yahoo.com.br.

${ }^{3}$ Universidade Federal do Piauí. E-mail: nildamas@uol.com.br.

${ }^{4}$ Universidade Federal do Piauí. E-mail: anapperonbio@gmail.com (autor para correspondências).
} 


\section{Introdução}

A concepção de que os conhecimentos científicos e tecnológicos devam fazer parte da formação do cidadão, se acentua na medida em que a ciência perde seu caráter de neutralidade e passa a ser debatida pela sociedade (CASAGRANDE, 2006). Nesse cenário, a escola passa a ser reconhecida como o ambiente primordial para a partilha e produção de conhecimentos, bem como para a formação do cidadão crítico. No entanto, de acordo com Xavier (2006), nem sempre o acesso e permanência dos jovens na escola têm garantido esse perfil de cidadão, fato este grandemente verificado quando se avalia o ensino de biologia e a formação da consciência crítica.

Atualmente, no Brasil, apesar das inovações científicas e tecnológicas fazerem parte dos currículos escolares das escolas públicas, grande parte dos alunos não contextualiza o ensino de biologia, com destaque aos conteúdos de genética, que se tem na escola com a sua realidade. Assim, Oca (2005) relata que os conteúdos de genética na educação básica pública, muitas vezes, são considerados difíceis e desinteressantes, não permitindo ao aluno fazer a correlação de que tópicos como ciclo celular, constituição e funcionamento da molécula de DNA, entre outros, abordados em sala de aula são a base para a criação de tecnologias que darão origem, por exemplo, aos transgênicos.

Portanto este trabalho teve por objetivo fazer um relato sucinto da importância do ensino de biologia nas escolas públicas brasileiras, com destaque ao tópicos de genética, para a formação de um indivíduo crítico frente às inovações científicas e uma breve reflexão sobre os principais problemas que impossibilitam a não concretização dessa formação.

\section{Desenvolvimento}

\section{O ensino de biologia e a formação do indivíduo crítico}

A Biologia é uma grande área das ciências que estuda os mecanismos de regulação dos organismos e as interações dos seres vivos com o meioambiente (CASAGRANDE, 2006). Dessa forma, compreendendo a importância e aplicabilidade dessa ciência o indivíduo tem condição de se posicionar, de forma coerente, frente a temas diversos da sociedade moderna.

Para Krasilchik (2000), a compreensão do ensino de biologia possibilita ao aluno a capacidade de assimilar, refletir, criticar e aprofundar seus conhecimentos em relação aos processos biológicos e a entender a importância dos mesmos na construção de tecnologia que irão gerar produtos que beneficiarão ou não a sociedade.

Complementando a citação de Krasilchik (2000), Silva, Cicillini (2008) ressaltam que mais do que fornecer informações, o ensino de biologia deve permitir ao educando o desenvolvimento de habilidades e competências para compreensão, sistematização e reelaboração de fatos. Assim, Carabetta (2010) afirma que para a realização desta tarefa é necessário que o educador planeje procedimentos didáticos que instiguem o aluno a refletir e aplicar os conteúdos dados em sala de aula na resolução de situações problemas.

Em 2002, os Parâmetros Curriculares Nacionais para o Ensino Médio já almejavam que a área de ciências da natureza propiciasse um aprendizado útil a vida e ao trabalho, e desenvolvesse no aluno da escola pública competências, habilidades e valores que lhes permitissem uma visão crítica sobre a natureza das ciências e do conhecimento científico.

Corroborando a citação acima, Silva (2003, p. 20) ressalta que:

Os alunos devem ir à escola para adquirir habilidades que os capacitem absorver os conhecimentos de que necessitam de maneira mais proveitosa por 
meio da prática da leitura, do raciocínio lógico, do planejamento e da avaliação de objetivos, etc. Desse modo, estaremos formando indivíduos abertos à realidade, capazes de reformular constantemente os conhecimentos adquiridos e atualizando-se sempre que perceberem a necessidade disso. Nossos alunos devem ter consciência de que as ciências progridem e as verdades de hoje poderão não ser as verdades de amanhã, mas que eles poderão sempre, a qualquer momento, tomar posse das novas verdades instauradas pelo progresso, graças às habilidades adquiridas na escola.

Porém, apesar de todo o apelo feito para que o ensino de biologia, na educação básica das instituições públicas, promova a construção da consciência crítica, Vilela (2007) e Vasconcelos (2002) citam que um problema bastante comum neste ensino, além do despreparo e desatualização de alguns professores, é a forma superficial, porém descrita de maneira complexa, de como alguns conteúdos são abordados nos livros didáticos, como grande destaque tópicos de genética.

\section{A ausência da contextualização no ensino de genética}

A genética é a ciência da hereditariedade e o ramo da biologia que estuda os mecanismos de transmissão das características de uma espécie, passados de uma geração para outra, além das variações que ocorrem na transmissão das características e a importância delas na constituição dos organismos e na construção de tecnologias. A genética aplicada é a base para a construção de biotecnologias e também fornece as ferramentas para a construção das técnicas de biologia molecular (CASAGRANDE, 2006). Para Paiva, Martins (2005), os avanços biotecnológicos e a necessidade de um posicionamento crítico frente a estes, colocam essa área em uma posição de destaque no ensino de biologia das escolas públicas brasileiras, com importantes implicações nas questões éticas da sociedade.

No Brasil, os tópicos da genética fazem parte do conteúdo de biologia ensinado na $3^{\mathrm{a}}$ série do ensino médio. Porém, a genética, como disciplina, não é bem aceita pela maioria dos discentes do ensino público em função de sua complexidade.
Para Vilela (2007) essa problemática se deve em grande parte ao não preparo adequado do docente que ministra a disciplina, pela falta de associação dos conteúdos dados frente a realidade no qual o aluno está inserido e pela forma abstrata de como os conteúdos são abordados em alguns livros didáticos.

Segundo Borges, Lima (2007) e Durbano et al. (2008), boa parcela dos alunos brasileiros sai do ensino médio entendendo, por exemplo, que as leis de Mendel são apenas "letras" que se combinam em um cruzamento, não conseguindo fazer a associação de que essas "letras" como AA ou Aa, que são apenas símbolos, são seqüências nucleotídicas, que representam os genes, e estão localizadas nos cromossomos, se segregando durante a meiose para a formação dos gametas. Mais do que isso as leis de Mendel são a base para a compreensão das características hereditárias passadas de geração a geração como o aparecimento em uma geração da prole de uma determinada doença, ou então para produzir uma prole de animais de interesse econômico.

Isto pode ser verificado em um trabalho realizado por Fabrício et al. (2006), com 136 alunos, do $3^{\circ}$ ano do ensino médio, de escolas públicas estaduais da região metropolitana da cidade de Recife, Pernambuco, onde avaliou-se os conhecimento deste público sobre as leis de Mendel. A partir dos resultados estes autores verificaram que a maioria dos alunos entrevistados não soube definir gene, não soube associar o gene as leis e a grande maioria associou as leis apenas com as letras que simbólica e didaticamente representam os genes durante a segregação na meiose.

Segundo Bastos (1995), Alves (2001) e Martins et al., (2010), muitos alunos também não conseguem fazer a associação entre alelo, gene, cromatina e cromossomo, e entender que essas estruturas estão ou fazem parte de uma mesma molécula que é o DNA. A não compreensão desses princípios básicos de genética conseqüentemente afeta o entendimento das técnicas atuais de biologia molecular. 
Em consoante a citação acima, esta problemática foi verificada em um trabalho realizado por Silva, Ciccilini (2008) com alunos do ensino médio de uma escola pública e de uma escola particular na cidade de Floriano, Piauí, onde se verificou o conhecimento dos alunos sobre DNA, ácidos nucléicos, clone, transgênico, terapia gênica e células-tronco. Os resultados mostraram que tanto os alunos da escola particular como os alunos da escola pública tiveram grande dificuldade em responder a parte básica do questionário que era sobre ácidos nucléicos e consequentemente responderam de forma equivocada as perguntas sobre os outros termos em específico, ou seja, aqueles voltados a biologia molecular.

Pedrancini et al. (2007) realizaram entrevistas com alunos do $3^{\circ}$ ano do ensino médio de escolas particulares e estaduais de dois municípios da região noroeste do Paraná com a finalidade de se avaliar alguns conceitos básicos em biologia, com enfoque a genética como a composição química da célula, composição química e função do DNA e a relação entre DNA, cromossomos e genes. Os resultados mostraram que os alunos tiveram dificuldades em responder quais são os componentes que constituem uma célula. Muitos consideraram os cromossomos como células, tiveram dificuldades em apontar a localização do DNA na célula e a grande maioria não soube dizer que os genes estão localizados no DNA.

Dessa forma, evidencia-se que com os avanços na área de biologia molecular muitos conceitos de genética são novos para a sociedade apesar da maciça divulgação feita pelos meios de comunicação, tal como aqueles relacionados à clonagem terapêutica e a terapia gênica.

Para Kohlein, Peduzzi (2005) e Casagrande (2006) a genética é a disciplina que, dentro da biologia, tem sofrido importantes mudanças nos últimos tempos, tanto em seus aspectos tecnológicos quanto conceituais. A transformação que essa área tem passado pode ser encarada como uma verdadeira revolução científica em função de ter causado profundas modificações em conceitos biológicos fundamentais. Sua contribuição ultrapassa os círculos acadêmicos e se difundem rapidamente por vários setores da sociedade com sérias implicações de ordem social, moral e econômica. Portanto, para que a população possa entender o grande espectro de aplicações e implicações da genética aplicada ou da biologia molecular, ela precisa de conhecimentos básicos que devem ser adquiridos na escola.

Corroborando a citação feita por Casagrande (2006), Giacóia (2006, p. 25) ressalta que:

\begin{abstract}
O avanço do conhecimento genético não se limita apenas a responder questões relativas á identificação dos genes, mas a entender melhor e mais rapidamente como funciona a vida no planeta. Nessa perspectiva, o papel da escola básica é fornecer aos estudantes os aportes necessários para compreender essas informações de maneira mais efetiva, à medida que elas colocam cotidianamente em cheque nossos conhecimentos, convicções e princípios éticos.
\end{abstract}

A imensa quantidade de informações produzidas a cada ano em pesquisas na área da genética gera insegurança não apenas por parte dos alunos, mas também por parte dos professores de biologia os pressionando a se atualizarem freqüentemente em relação aos avanços dessa área (ÁRIAS, 2004; CAMARGO; INFANTE-MALACHIAS, 2007).

\section{As dificuldades no ensino de biologia}

O professor de biologia tem sido historicamente exposto a uma série de desafios que o obrigam a acompanhar as descobertas científicas e tecnológicas, e o grande desafio é a construção coletiva do conhecimento de forma sistematizada e acessível, o que leva tempo, estudo e dedicação.

Grande é a carga horária dos professores do ensino médio, principalmente das escolas públicas. Essa carga excessiva faz com que o professor não tenha tempo hábil para se preparar e se atualizar. $\mathrm{O}$ avanço nas áreas da ciência, como por exemplo, na área de genética, acontece rapidamente e muitos docentes não conseguem atualizar-se em tempo hábil. Muitos 
professores também possuem dificuldades para conviver com as novas tecnologias e com linguagens do mundo atual, podendo fazer com que a formação do professor seja considerada arcaica poucos anos depois de sua formação (ARRUDA, 1994; DINIZ; SCHALL, 2001; JUSTINA; BARRADAS, 2004).

Segundo Diniz, Schall (2001) e Lopes, Melo (2005) outro grande problema do professor de Biologia não conseguir fazer a conexão do que é visto em sala de aula com o que é exposto nos meios de comunicação é a inexistência ou então a existência precária de laboratórios e/ou equipamentos nas escolas públicas. A falta de recursos, inexistência de laboratórios e/ou equipamentos e ainda a falta de tempo têm sido algumas das dificuldades alegadas pelos professores para a realização de práticas pedagógicas inovadoras.

Seguindo esse raciocínio Lima, Vasconcelos (2006, p. 10) ressaltam que:

O docente, por falta de autoconfiança, de preparo, ou por comodismo, restringe- se a apresentar aos alunos, com o mínimo de modificações, o material previamente elaborado por autores que são aceitos como autoridades. Apoiado em material planejado por outros e produzido industrialmente, o professor abre mão de sua autonomia e liberdade, tornando-se simplesmente um técnico.

Para a oferta de um bom ensino de biologia, com destaque a genética, se faz necessário que o professore tenha a sua disposição recursos didáticos que propiciem a relação teoria - prática. A falta de recursos didáticos pode colaborar para má formação de conceitos e incompreensão de conteúdos. Para Libâneo (2001):

Os professores precisam dominar, com segurança, esses meios auxiliares de ensino, conhecendo-os e aprendendo a utilizá-los. O momento adequado de utilizá-los vai depender do trabalho docente prático, no qual se adquirirá o efeito traquejo na manipulação do material didático.

Mas não se pode perder o foco de que a simples presença do aparato tecnológico na sala de aula não garante mudanças na forma de ensinar e aprender. "A tecnologia deve servir para enriquecer o ambiente educacional, proporcionando a construção do conhecimento por meio de uma atuação ativa, crítica e criativa por parte de alunos e professores." (BRASIL, 2002).

O educador de biologia deve estar atualizado para diminuir a problemática do ensino-aprendizagem através do domínio dos temas relacionados à área. Os professores de biologia são constantemente expostos a situações que demandam posicionamento crítico e discussões sobre temas complexos e polêmicos como, por exemplo: cultivo de células tronco, clonagem terapêutica ou reprodutiva, alimentos transgênicos, etc. (AYUSO; BANET, 2002; TIZIOTO; ARAÚJO, 2007).

Para Bozanini (2005); Rodrigues (2009), Carabetta (2010), o ensino de biologia possui caráter pouco motivador e desafiador para os educandos em função de uma prática docente desvinculada da realidade; na falta de estimulação do pensamento crítico; de currículos divergentes entre o fazer e o pensar a ciência; da desconsideração dos conhecimentos prévios que os alunos trazem para a escola, provenientes de sua própria vivência, da restrição do conteúdo, reduzindo-o apenas ao livro didático e, ocasionando, dessa forma, um ensino passivo e desprovido de contextualização.

Para Krasilchic (2000, p. 10):

\begin{abstract}
Alunos do ensino fundamental da rede pública na maioria das vezes deparam-se com metodologias que nem sempre promovem a efetiva construção de seu conhecimento. Tampouco lhes são oferecidos mecanismos de compensação por defasagens sociais, que vão desde problemas de natureza familiar ao limitado acesso a livros, sites e outras fontes de conhecimento. Cabe ao educador em biologia superar tais obstáculos, construindo possibilidades de mudança, ao estimular atividades que priorizem questões de Ciências, Tecnologia e Sociedade (CTS).
\end{abstract}

Portanto, para minimizar as problemáticas enfrentadas no processo de ensino aprendizagem o professor deve atualizar-se através da participação de formações continuadas. A formação continuada é uma estratégia para superar resultados não atingidos na formação anterior e ampliar os conhecimentos já estabelecidos, também ajuda o docente no desenvolvimento de práticas pedagógicas inovadoras. 


\section{Conclusão}

A partir dessa breve revisão pode-se verificar que ainda é grande o "abismo" entre o ensino de biologia, com ênfase a genética, com os acontecimentos diários dos alunos em meio á sociedade na qual eles estão inseridos. Este problema se deve a fatores como a precarização da formação docente, excessivas cargas horárias de trabalho, utilização do livro didático como instrumento único de ensino, conteúdos abstratos e superficiais, ausências de aparato tecnológico no ambiente escolar, ausência de atividades interdisciplinares e contextualizadas.

Muito já se avançou no ensino de biologia, porém, muito ainda precisa ser feito para que além de ter conhecimento básico sobre essa ciência o aluno também possa, a partir dela, exercer o seu direito de cidadania, como um indivíduo crítico frente aos acontecimentos e decisões científicas oriundas dessa ciência.

\section{Referências}

ALVES, N. F. Formação de professores: pensar e fazer. São Paulo: Cortez, 2001.

ÁRIAS, A. Em 1953 foi descoberta a estrutura do DNA: etapas de um grande avanço científico. Passo Fundo: Embrapa, 2004.

ARRUDA, S. M.; VILLANI, A. Mudança conceitual no ensino de ciências. Caderno Catarinense de Ensino de Física, Florianópolis, v. 11, n. 12, p. 88-99, 1994.

AYUSO, G.; BANET, E. Alternativas a la enseñanza de la genética en educación secundaria. Enseñanza de la Ciências, Chile, v. 20, n. 1, p. 133-157, 2002.

BASTOS, F. Construtivismo e ensino de ciências. São Paulo: Escrituras, 1995.

BONZANINI, T. K. Avanços recentes em biologia celular e molecular, questões éticas implicadas e sua abordagem em aulas de biologia no ensino médio: um estudo de caso. 2005. 123 f. Dissertação (Mestrado em Educação para Ciência) - Faculdade de Ciências, Bauru, 2005.
BORGES, R. M. R; LIMA, V. M. R. Tendências contemporâneas do ensino de biologia no Brasil. Revista Eletrônica de Enseñanza de las Ciências, Chile, v. 6, n. 2, p. 299-309, 2007. Disponível em: $<$ http://www.sauem.uvigo.es/reec/>. Acesso em: 20 jul. 2007.

BRASIL. Parâmetros Curriculares Nacionais $P C N$ : ensino médio. Brasília: MEC/SEMTEC, 2002.

CAMARGO, S.; INFANTE-MALACHIAS, M. A genética humana no ensino médio: algumas propostas. Genética na Escola, Ribeirão Preto, v. 2, n. 1, p. 14-16, 2007.

CARABETTA, V. J. Uma investigação microgenética sobre a internalização de conceitos de biologia por alunos do ensino médio. Revista Contemporânea de Educação, Rio de Janeiro, v. 5, n. 10, p. 1-10, 2010.

CASAGRANDE, G. L. A genética humana no livro didático de biologia. 2006. 103 f. Dissertação (Mestrado em Educação Científica e Tecnológica) - Universidade Federal de Santa Catarina, Florianópolis, 2006.

DINIZ, M. C.; SCHALL, V. Estudo exploratório sobre estratégias e materiais educativos. In: ENCONTRO NACIONAL DE PESQUISA EM EDUCAÇÃO EM CIÊNCIAS (ABRAPEC), 3., 2001, Atibaia. Anais... Atibaia: ABRAPEC, 2001.

DURBANO, J. P. M.; PADILHA, I. Q. M.; RÊGO, T. G.; RODRIGUES, P. A. L.; ARAÚJO, D. A. M. Percepção do conhecimento dos alunos de ensino médio do município de João Pessoa sobre temas emergentes em biotecnologia. In: CONGRESSO BRASILEIRO DE GENÉTICA, 54., 2008, Salvador. Anais... Salvador: SBG, 2008.

FABRÍCIO, M. F. L.; JOFÓLI, Z. M. F.; SEMEN, L. S. M.; LEÃO, A. M. A. C. A compreensão das leis de Mendel por alunos de biologia na educação básica e na licenciatura. Ensaio - Pesquisa em Educação em Ciências, Uberlândia, v. 8, n. 1, p. 12-25, 2006. 
GIACÓIA, L. R. D. Conhecimento básico de genética: concludentes do ensino médio e graduandos de Ciências Biológicas. 2006. Dissertação (Mestrado em Educação para a Ciência) - Universidade Estadual de São Paulo, Bauru, 2006.

JUSTINA, L. A. D.; BARRADAS, C. M. As opiniões sobre o ensino de genética numa amostra de professores de biologia no nível médio. Porto Alegre: ABRAPEC, 2004.

KÖHNLEIN, J. F. K.; PEDUZZI, L. O. Q. Uma discussão sobre a natureza da ciência no ensino médio: um exemplo com a teoria da relatividade restrita. Caderno Brasileiro de Ensino de Física, Florianópolis, v. 22, n. 1, p. 36-70, 2005.

KRASILCHIC, M. Reforma e realidade: o caso do ensino de ciências. São Paulo em Perspectiva, São Paulo, v. 14, n. 1, p. 85-93, 2000.

LIBÂNEO, J. C. Adeus professor, adeus professora? São Paulo: Cortez, 2001.

LIMA, K. E. C.; VASCONCELOS, S. D. Análise da metodologia de ensino de ciências nas escolas de rede municipal de Recife. Ensaio: Avaliação e Políticas em Educação, Rio de Janeiro, v. 14, n. 52, p. 397-412, 2006.

LOPES, M. A.; MELO, I. S. Bioprospecção: biotecnologia aplicada a prospecção e uso de serviços e funções da biodiversidade. Biotecnologia, Ciência e Desenvolvimento, São Paulo, v. 34, p. 29-35, 2005.

MARTINS, I. Clonagem na sala de aula: um exemplo de uso de didática de um texto de divulgada científica. Rio de Janeiro: Faculdades da UFRJ, 2010.

OCA, I. C. M. Que aportes oferece La investigación reciente sobre aprendizagem para fundamentar nuevas estrategias didácticas? Revista Educación, México, v. 19, n. 1, p. 7-16, 2005.

PAIVA, A. L. B.; MARTINS, C. M. C. Concepções previas de alunos de terceiro ano do ensino médio a respeito de temas na área da genética. Minas Gerais: UFMG, 2005.
PEDRANCINI, V. D.; GALUCH, M. T. B.; MOREIRA, A. L. O. R.; RIBEIRO, A. C. Ensino e aprendizagem de biologia no ensino médio e apropriação do saber científico e biotecnológico. Revista Electrónica de Enseñanza de las Ciências, Chile, v. 6, n. 2, 2007.

RODRIGUES, S. P. Uma contribuição para o ensino da sistemática em sala de aula: relato de experiências sobre a classificação de animais de Aristóteles e Linné. São Paulo: PUC, 2009.

SILVA, M. O.; CICILliNI, G. A. O potencial das discussões polêmicas nas aulas de Biologia. In: UNIVERSIDADE, NECESSÁRIAS UTOPIAS E DISTOPIAS; SEMANA DO SERVIDOR, 4.; SEMANA ACADÊMICA, 5., 2008, Uberlândia. Atas... Uberlândia: Universidade Federal de Uberlândia, 2008. p. 1-7.

SILVA, V. O uso do software como recurso didático no ensino de ciências e biologia. 2003. $105 \mathrm{f}$. Dissertação (Mestrado em Educação Científica e Tecnológica) - Universidade Federal de Santa Catarina, Florianópolis, 2003.

TIZIOTO, P. C.; ARAÚJO, E. S. N. N. Biotecnologia e bioética nos livros didáticos. In: ENCONTRO NACIONAL DE PESQUISA EM EDUCAÇÃO (ABRAPEC), 6., 2007, Florianopolis. Anais... Florianópolis: ABRAPEC, 2007.

VASCONCELLOS, C. S. Construção do conhecimento em sala de aula. São Paulo: Lebertad, 2002.

VILELA, M. R. A produção de atividades experimentais em genética no ensino médio. 2007. 50 f. Monografia (Especialização em Ensino de Ciências por Investigação) - Universidade Federal de Minas Gerais, Belo Horizonte, 2007.

XAVIER. M. C. F. A nova biologia e a genética nos livros didáticos de biologia no ensino médio. Ciência e Educação, Bauru, v. 12, v. 3, p. 275-289, 2006. 
